\title{
Updates on the Electrocardiogram in Acute Coronary Syndromes
}

\author{
Stephen W. Smith
}

Published online: 23 December 2012

(c) Springer Science+Business Media New York 2012

\begin{abstract}
The electrocardiogram (ECG) is the initial test in patients with suspected ACS. The ECG is the defining element of ST-segment elevation myocardial infarction (STEMI). Its most important use is in the detection of acute coronary obstruction, and it is the most important, cost-effective, and immediately available initial test in the decision for emergency reperfusion therapy. There is a recent interest in refining the sensitivity and specificity of the ECG for coronary occlusion, and thus for identifying subtle STEMI, as well as in recognizing pseudoinfarction patterns and thus avoiding false positive cath lab activations. Studies assessing the accuracy of cath lab activation, the differentiation of precordial ST-segment elevation due to normal variant from that of anterior STEMI, the diagnosis of STEMI in the presence of left bundle branch block, the differentiation of benign inferior ST-segment elevation from that of inferior STEMI, and the importance of ST-segment elevation in lead aVR will be discussed.
\end{abstract}

Keywords Electrocardiogram · ST-segment elevation myocardial infarction (STEMI) - Coronary occlusion · Acute coronary syndromes - STEMI-equivalent . Catherization laboratory activation

S. W. Smith $(\bowtie)$

Hennepin County Medical Center, University of Minnesota, HCMC EMS, ER-R-2, 701 S. Park Ave., Minneapolis, MN 55419, USA

e-mail: smith253@umn.edu

\section{Introduction}

The Electrocardiogram in Acute Coronary Syndromes: Recent Articles

The electrocardiogram (ECG) continues to be the initial clinical test in patients with suspected acute coronary syndromes (ACS). Recently there has been an increased focus on the accuracy of the ECG interpretation, on the misinterpretation rate, and on false positive and false negative cath lab activation rates. There has also been some effort to find specific ECG features that may help to distinguish true ACS ECGs from non-ACS ECGs that mimic ACS. We will cover some of the most important below.

Pseudoinfarction, Missed STEMI, and Appropriate Cath Lab Activation

Every physician who treats patients with chest pain knows that the differential diagnosis of ST-segment elevation (STE) includes more than just ST-segment elevation myocardial infarction (STEMI), and knows also that the ECG diagnosis is not always easy. The "pseudoinfarction" patterns include, but are not limited to, early repolarization, left ventricular aneurysm morphology, pericarditis, left ventricular hypertrophy $(\mathrm{LVH})$, WPW, Brugada and, of course, left bundle branch block (LBBB).

To demonstrate this, Jayroe et al. [1] distributed difficult ECGs to 15 "expert" electrocardiographers (all cardiologists), with a clinical scenario suggestive of ischemia. There were 108 nonischemic ECGs with STE of various causes and eight STEMIs; mean sensitivity and specificity of the readers were $75 \%$ and $85 \%$, respectively. This was similar to Turnipseed's 2005 study [2] in which neither emergency physicians nor cardiologists performed well in 
differentiating early repolarization from STEMI. More recently, Tran et al. [3] studied the ECGs and records of 240 consecutive catheterization laboratory activations for STEMI. They excluded patients with LBBB or paced rhythms and others whose STE criteria did not meet guideline-based criteria for acute STEMI. They did detailed chart reviews to determine if there was or was not actually a STEMI, in retrospect, by examining cath results, echocardiograms, biomarkers, etc. They then showed these ECGs to seven experienced interventional cardiologists and asked them to interpret the ECGs, blinded the outcome, and asked whether they would recommend immediate percutaneous coronary intervention (PCI), assuming that the patient had appropriate ischemic symptoms. Of 84 subjects, there were 40 patients with a true STEMI and 44 without (13 of whom had non-STEMI). Recommendations for immediate PCI varied widely, from 33 to $75 \%$. Sensitivities were $53-83 \%$ (mean, $71 \%$ ), specificities $32-86 \%$ (mean $63 \%$ ); PPV ranged from 52 to $79 \%$ (mean $66 \%$ ) and NPV ranged from 67 to $79 \%$ (mean $71 \%$ ). When the readers chose non-ischemic ST elevation, LVH was thought to be the cause in 6-31\% and old MI/ LV aneurysm in 10-26\%. Thus, even among the "experts", STE is very difficult to interpret.

Past studies show that only $67-80 \%$ of STEMI patients whose ECGs make them clearly eligible for reperfusion therapy receive it [4-6]. In 2008, Tricomi et al. [7] found that only $78 \%$ of patients clearly eligible for reperfusion therapy received it. One third of those had unrecognized STE.

However, there are many coronary occlusions which do not, even in retrospect, get classified as STEMIs. Wang et al. recently showed that in $28 \%$ of non-STEMIs, the infarct-related artery (IRA) is occluded, and that in these patients biomarker levels and mortality are higher than in non-STEMIs without an occluded IRA. However, there is no in-depth ECG analysis to discover ECG findings helpful in identifying this group [8•]. From et al. [9] similarly showed that one fourth of non-STEMIs have an occluded IRA, and that $20 \%$ of these were right coronary, $17 \%$ left anterior descending (LAD), and $30 \%$ were circumflex artery occlusions. These would be "STEMI-equivalents" (the term for ACS which has occlusion or near occlusion, but in the absence of classic ST elevation; there is potential for imminent irreversible loss of myocardium, and emergent angiography and PCI may be indicated) [10]. I have personally seen ECGs of many patients who had a coronary occlusion that was not recognized, but whose subtle ECG findings were diagnostic or highly suggestive, such that further immediate investigation with echocardiography or angiography would be warranted. As in the study of Wang et al., these patients later ruled-in for acute myocardial infarction (AMI) by very high biomarkers, got a non-urgent angiogram and were diagnosed with non-STEMI in spite of coronary occlusion and subtle STE. Even the aforementioned studies underestimate the number of missed occlusions, as it is well known that by the time of a delayed angiogram in patients with known, diagnosed STEMI, $20-25 \%$ of occluded arteries have recanalized (spontaneously reperfused without therapy or due to therapy for nonSTEMI) [11, 12]. These patients often have very high biomarker levels and a significant wall motion abnormality. Unfortunately, few studies other than those mentioned have looked at the rate of failure to diagnose coronary occlusion (false negative cath lab activation rate). One study asserted that "there were no cases in which STEMI was not recognized by the emergency physician during the study period;" however, they only reviewed cath lab activation cases and so could only possibly find false positives, not false negatives [13]. Thus, we are only beginning to discover the true incidence of missed STEMI-equivalents, and are at an even more rudimentary stage of identifying them on the ECG.

Conversely, there is a body of literature which assesses false positive activations. A study from 2007 showed an approximate $10 \%$ rate of normal coronaries in patients who are referred for immediate PCI for STEMI; in this study, false positives were underestimated because patients with non-STEMI, and sometimes those with simple stable coronary disease, were not considered false positives [14]. In a study by Kontos et al. [13], false positives were assessed by use of millimeter criteria, which may be very nonspecific [15]. Garvey et al. [16] studied 3,973 cath lab activations at 14 PCI hospitals, and used the interventionalists' opinions (cancellation of cath lab activation) as the outcome measure for whether cath lab activation was "appropriate." But it is clear from Tran et. al. (discussed above) [3] that interventionalists' opinions are not an appropriate reference standard. Two other studies found 7.2 and $17 \%$ of STEMI cath lab activations were false alarms $[17,18]$. However, their endpoints for "false positive" were defined by "no culprit lesion found," an inappropriate endpoint: non-STEMIs also have culprit lesions and to routinely activate the cath lab emergently in these cases is usually an inappropriate use of resources.

Finally, only one study I am aware of has addressed the problem of false positive activations appropriately [19]. In this study, a true positive required a flow grade less than thrombolysis in myocardial infarction (TIMI) grade 3 flow in at least one artery, and found that $36 \%$ of cases were false positive activations. This study was criticized by editorialists for using a retrospective methodology [20]. It is indeed inappropriate to use retrospective analysis to criticize those who activate the cath lab, but it is only through analysis of cases that do not have TIMI-3 flow, vs. those that do, that we can improve ECG criteria for activation. Unfortunately, this study did not do ECG analysis. 
Thus, studies looking at false positive rates use as outcome measures: (1) an "expert" interpretation [16] or; (2) the presence of a positive biomarker (troponin) at any level and an angiographic culprit lesion, whether occluded or not [14] or; (3) STE criteria [13]. In a different study by Kontos et al. [21], of LBBB, there was an assessment of biomarker level $(\mathrm{CK}-\mathrm{MB})$ at $5 \times$ the upper limit of normal. In our retrospective study of LBBB [22••, 23-25] we required documented occlusion or a culprit lesion with a peak troponin I of at least $10 \mathrm{ng} / \mathrm{ml}$, as most true STEMI have at least this level, and most true non-STEMI do not [26-29]. Until all ECG in ACS studies consistently assess ECG features of ischemia during proven occlusion, and contrast them to those who are proven not to have occlusion, we will make little progress on improving ECG recognition of this coronary event. Thus, in order to better elucidate which ECG findings are indicative of occlusion, we need more angiographically-based ECG research.

In any case, there has been a recent effort to expand on the ECG indications for immediate reperfusion, and these include such purported STEMI-equivalents as new, or presumed new, LBBB, pre-existing LBBB with Sgarbossa concordance, isolated posterior MI, ST elevation in aVR because of its association with left main ACS, de Winter's $\mathrm{ST} / \mathrm{T}$-waves, and hyperacute T-waves [10]. We will cover some of these in the following paragraphs.

\section{Differentiation of Anterior Normal Variant ST Elevation from Anterior STEMI}

This year, we published a study attempting to differentiate the ST elevation of early repolarization (normal variant ST elevation) from that of anterior STEMI due to LAD occlusion [22••]. In this retrospective study with derivation and validation groups, we looked at 355 consecutive anterior STEMIs and chose the 143 "subtle," or "non-obvious," ones, as defined by $<5 \mathrm{~mm}$ of STE, no inferior reciprocal ST depression, no Q-waves in $\mathrm{V} 2-\mathrm{V} 4$, no anterior $\mathrm{T}$-wave inversion, concave upward ST segments in V2-V5, and no terminal QRS distortion, and compared them with the ECGs of 241 patients with proven early repolarization, focusing on the 171 with at least $1 \mathrm{~mm}$ of STE. We looked at the R-wave amplitude in V2-V4, T-wave amplitude in V2-V4, Bazett computerized corrected QT interval (QTc), ST segment elevation at the J-point and at $60 \mathrm{~ms}$ after the J-point, both relative to the PR segment, T-wave to R-wave amplitude ratio in V2-V4, upward concavity, J-wave notching, upright $\mathrm{T}$-wave in $\mathrm{V} 1$, and $\mathrm{T}$-wave in $\mathrm{V} 1>\mathrm{T}$-wave in $\mathrm{V} 6$, and found that the single best predictor was R-wave amplitude. By logistic regression, we derived and validated an equation, or formula, based on three measurements ( $\mathrm{R}$-wave amplitude in lead V4, STE $60 \mathrm{~ms}$ after J-point in lead V3, and computerized QTc) for differentiating STEMI from early repolarization, such that the equation $([1.196 \times \mathrm{ST}$ elevation at $60 \mathrm{~ms}$ after the $\mathrm{J}$ point in lead V3 in $\mathrm{mm}]+[0.059 \times$ QTc in ms] - [0.326 $\times$ R-wave amplitude V4 in $\mathrm{mm}])>23.4$ predicted STEMI and $\leq 23.4$ predicted early repolarization in both groups, with overall sensitivity, specificity, and accuracy [ \pm confidence intervals (CI)] of $86 \%(79,91), 91 \%(85,95)$, and $88 \%(84,92)$, respectively, with a positive likelihood ratio of 9.2 (95\% CI, 8.5-10) and negative likelihood ratio of 0.1 (95\% CI, 0.08-0.3). Overall, if exclusions are included as true positives, it was $94 \%$ sensitive and $87 \%$ specific. See Fig. 1 for a case of subtle LAD occlusion that can be diagnosed with the formula.

Furthermore, the degree of upward concavity, upright $\mathrm{T}$-wave in V1, T-wave in V1 taller than T-wave in V6, nor J-wave notching added value to the ECG criterion. Moreover, the 3-variable ECG criterion performed far better than any of the many published STE criteria, none of which had any important diagnostic utility (see Table 1). In an abstract published by Turnipseed, of over 1,000 consecutive patients with chest pain, there were only two anterior STEMI (no denominator given) that had at least two leads with a J-wave notch of at least $0.5 \mathrm{~mm}$ [30] In our study, although $14 \%$ of STEMI (vs. $32 \%$ of early repolarization) had at least one lead with a $0.5 \mathrm{~mm} \mathrm{~J}$-wave notch, only 5 of 143 had two such leads vs. 9 of 171 in early repolarization (unpublished data). Thus, presence or absence of J-wave notching did not add to our overall rule.

\section{A "New" Sign of LAD Pcclusion ("de Winters"} T-Waves)

Another subtle sign of LAD occlusion was recently studied. Verouden et al. [33•] found that 35 (2\%) of 1890 patients undergoing primary PCI of an occluded LAD had a distinct pattern of precordial ST depression of at least $1 \mathrm{~mm}$ at the J-point, followed by upsloping ST segments that continued into tall and symmetric ("hyperacute") T-waves (see Fig. 2). These had been less systematically reported several times [34-36].

\section{Differentiation of Normal Variant Inferior ST Elevation} and that of Pericarditis from that of Inferior Wall STEMI: Lead aVL

Inferior STE may be due to a variety of conditions, and it may be difficult to accurately diagnose subtle inferior STEMI. In order to better understand this, we studied 156 patients with inferior STEMI and compared them to $39 \mathrm{ED}$ chest pain patients with a discharge diagnosis of pericarditis (all ruled out for AMI) with inferior ST elevation and to 66 patients with baseline inferior ST elevation (limb lead early repolarization pattern). All but one inferior STEMI 


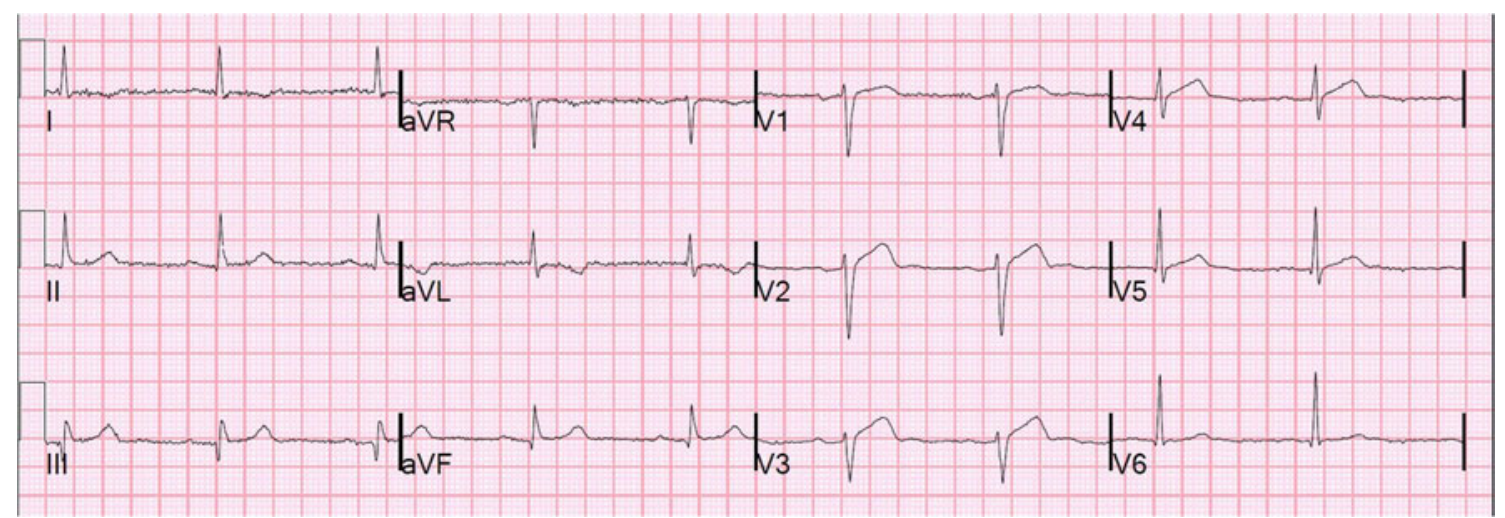

Fig. 1 This was an elderly male with chest pain. The ECG shows slightly more than $1 \mathrm{~mm}$ of ST-segment elevation in leads V2 and V3 at the J-point. The faculty physician thought this was normal. The resident applied the formula, based on three measurements (R-wave amplitude in lead V4 (RAV4) $=6.5 \mathrm{~mm}$, ST-segment elevation
$60 \mathrm{~ms}$ after J-point in lead V3 (STE60 V3) $=2.5 \mathrm{~mm}$, and computerized QTc $=399 \mathrm{~ms})([1.196 \times$ STE60 V3] $+[0.059 \times$ QTc in $\mathrm{ms}]-[0.326 \times \mathrm{RA} \mathrm{V} 4])$; the value of 24.41 is $>23.4$ and thus predicted STEMI. The cath lab was activated and a $100 \%$ LAD occlusion was found

Table 1 Diagnostic utility of various STEMI voltage criteria in subtle MI vs. ER, both derivation and validation groups combined $(n=314$; 143 STEMI, 171 ER)

\begin{tabular}{|c|c|c|c|}
\hline At least two consecutive leads with STE: & $\begin{array}{l}\text { Location of STE } \\
\text { measurement }\end{array}$ & $\mathrm{LR}+(95 \% \mathrm{CI})$ & $\mathrm{LR}-(95 \% \mathrm{CI})$ \\
\hline \multirow[t]{2}{*}{ 1) $\geq 1 \mathrm{~mm} \mathrm{~V} 1-\mathrm{V} 6$} & STEJ & $1.0(0.7,1.5)$ & $0.9(0.5,1.4)$ \\
\hline & STE60 & $1.0(0.9,1.0)$ & $5.0(0.6,45)$ \\
\hline \multirow[t]{2}{*}{ 2) $\geq 2 \mathrm{~mm}$ in any of $\mathrm{V} 1-\mathrm{V} 3$ or $\geq 1 \mathrm{~mm} \mathrm{V4-V6} \mathrm{[31]}$} & STEJ & $1.4(1.1,1.6)$ & $0.7(0.5,0.9)$ \\
\hline & STE60 & $1.2(0.9,1.5)$ & $0.6(0.4,0.9)$ \\
\hline \multirow[t]{2}{*}{ 3) $\geq 1 \mathrm{~mm} \mathrm{V1}$, V4-V6 or $\geq 2 \mathrm{mmV} 2-\mathrm{V} 3$} & STEJ & $1.3(1.0,1.5)$ & $0.7(0.6,0.9)$ \\
\hline & STE60 & $1.2(0.9,1.5)$ & $0.5(0.3,0.8)$ \\
\hline \multirow{2}{*}{$\begin{array}{l}\text { 4) } \geq 1 \mathrm{~mm} \text { V1, V4-V6 or } \geq 2 \mathrm{~mm} \mathrm{V2-V3} \mathrm{(men)} \mathrm{or} \geq 1.5 \mathrm{~mm} \text { in } \mathrm{V} 2-\mathrm{V} 3 \\
\text { (women) }\end{array}$} & STEJ & $1.3(1.0,1.6)$ & $0.7(0.5,0.9)$ \\
\hline & STE60 & 1.1. $(0.8,1.5)$ & $0.5(0.3,0.8)$ \\
\hline \multirow{2}{*}{$\begin{array}{l}\text { 5) } \geq 1 \mathrm{~mm} \text { in } \mathrm{V} 1, \mathrm{~V} 4-\mathrm{V} 6 \text {, or } \geq 2 \mathrm{~mm} \mathrm{~V} 2-\mathrm{V} 3 \text { (men) or } \geq 2.5 \mathrm{~mm} \text { in } \mathrm{V} 2-\mathrm{V} 3 \\
\text { (men }<40 \text { years old) or } \geq 1.5 \mathrm{~mm} \text { in } \mathrm{V} 2-\mathrm{V} 3 \text { (women) }[32]\end{array}$} & STEJ & $1.5(1.2,1.7)$ & $0.6(0.3,0.8)$ \\
\hline & STE60 & $1.2(0.9,1.6)$ & $0.3(0.2,0.6)$ \\
\hline \multirow[t]{2}{*}{ 6) $\geq 1 \mathrm{~mm}$, V5-V6 or $\geq 2 \mathrm{~mm} \mathrm{~V} 1-\mathrm{V} 4$} & STEJ & $1.7(1.4,2.0)$ & $0.7(0.5,0.9)$ \\
\hline & STE60 & $1.3(1.0,1.6)$ & $0.5(0.4,0.8)$ \\
\hline \multicolumn{2}{|c|}{ ECG criterion: STEMI if $>23.4:(1.196 \times$ STE60 V3 $)+(0.059 \times$ QTc $)-(0.326 \times$ RA V4 $)$} & $9.2(8.5,10)$ & $0.1(0.08,0.3)$ \\
\hline
\end{tabular}

STEMI ST-segment elevation myocardial infarction, STE ST-Segment elevation, $\mathrm{mm}=$ millimeters, STEJ ST-segment elevation at the J-point, relative to the PR segment, STE60 ST-Segment Elevation at $60 \mathrm{~ms}$ after the J-point, relative to the PR segment, QTc Bazett corrected QT interval (QT interval divided by the square root of the preceding R-R interval, in milliseconds

Positive likelihood ratios (LR+) approaching 10 and negative likelihood (LR-) ratios approaching 0.1 have been bolded

Reproduced with permission from Annals of Emergency Medicine 60(1):45-56

ECG had some amount of reciprocal ST depression in lead aVL, whereas none of the 105 controls had this finding. The initial ECG did not meet reperfusion "criteria" of $1 \mathrm{~mm}$ STE in two consecutive leads in $28 \%$ of cases, but in all of these there was some ST depression in aVL. Overall diagnostic performance of STD in aVL for STEMI vs. no-AMI were sensitivity $99 \%$ (95\% CI: 96-100\%) and specificity $100 \%$ (95\% CI: 95.6-100\%) [37]. We also found that, in pericarditis, ST elevation in lead II was always higher than in lead III. This is consistent with two studies by Spodick, in which all cases of pericarditis had an
ST axis between 0 and 90 (STE in lead II $>$ STE in lead III) [38, 39]. However, others recently found the exact opposite: only 19 of 122 "pericarditis" cases had ST elevation in lead II > III; this study is difficult to evaluate [40]. Finally, it is possible to have STE in lead II $>$ STE lead III simultaneous with ST depression in aVL if the ST axis is between $60^{\circ}$ and $90^{\circ}$, and approximately $10 \%$ of our cases fit this category. I have personally never seen a case of even inferolateral STEMI that did not have at least a hint of ST depression in lead aVL, but it is theoretically possible that STEMI with lateral ST elevation (leads V5, 


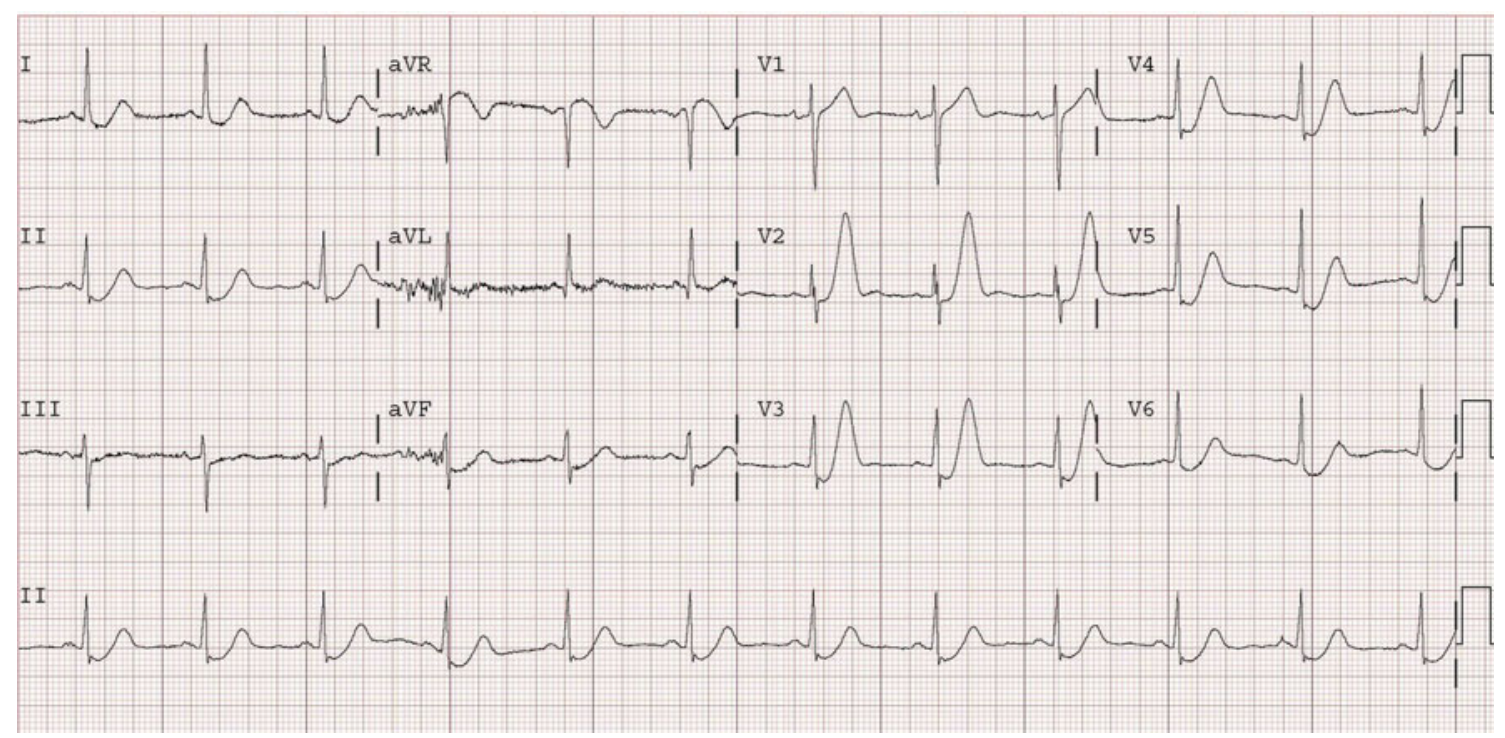

Fig. 2 de Winter's T-waves due to acute occlusion of the left anterior descending coronary artery. This is a STEMI-equivalent. There are large symmetric ("hyperacute") T-waves in leads V2-V5, with preceding ST-segment depression. This is diagnostic of LAD occlusion; nothing else will cause this
V6) may have a falsely isoelectric or elevated ST segment in lead aVL, and to assess these with great caution. I believe this is one of the most difficult of all infarction/ pseudoinfarction differential diagnoses. The inferolateral ECG leads are the most commonly involved ones in pericarditis (personal data), and these walls are also the most commonly involved by MRI analysis [41].

That there is no reciprocal STD in pericarditis conforms with previous thinking on these ST elevation variants, except that it is thought that patients with localized pericarditis may present with reciprocal ST depression if, for instance, the inflamed area of the heart is the inferior wall. The assertion has been made that regional ECG changes associated with pericarditis are due to postinfarction pericarditis [42]. However, we are not aware of data on this. Of 45 cases of apparent MI but with normal angiograms, 37 had myocarditis by Indium scintigraphy; although 23 had regional wall motion abnormalities, only two of these had any ST depression on the ECG [43].

It is important to understand that there are other etiologies of inferior ST-elevation with reciprocal ST depression in aVL that may be confused with inferior STEMI; these included Wolff-Parkinson-White syndrome, LVH of the limb leads, inferior left ventricular aneurysm morphology (persistent ST elevation after previous inferior MI), LBBB, and paced rhythm.

\section{Left Bundle Branch Block and AMI}

The ACC/AHA recommends reperfusion therapy for patients with ischemic symptoms and new LBBB, while also applying the Sgarbossa criteria [44]. The 2007 and 2009 focused updates do not further comment on this issue $[45,46]$. It is becoming increasingly clear that most such patients do not have AMI and especially do not have acute coronary occlusion. Past ED studies show that the incidence of AMI in ED chest pain patients, as diagnosed by CK-MB, is low, at about $13 \%$ [47, 48]. More recently, Chang et al. [49] found the incidence of troponin-diagnosed AMI in patients with LBBB at $5.2 \%$ and with new LBBB at $7.3 \%$. As approximately $30 \%$ of troponin-diagnosed AMI patients have STEMI [50], it is probable that only about 2-4 \% of patients with chest pain and LBBB have STEMI.

On the other hand, Kontos et al. [21] recently published data on 401 patients with LBBB undergoing a "rule-out AMI protocol." Of these, $64 \%$ had new (37\%) or presumably new (27\%) LBBB; 116 (29\%) of patients had AMI. Of those with at least $1 \mathrm{~mm}$ of concordant ST-segment deviation, $86 \%$ had AMI, and peak CK-MB at least $5 \times$ normal (used as a STEMI-equivalent surrogate) occurred in $50 \%$ of them vs. none of those who did not. A concordant ST segment was an important predictor of AMI (odds ratio 17). This study combined the data from Kontos' previous study [47], in which only 24 of $182(13 \%)$ consecutive patients had AMI, was included. The latter half of the study, with 219 patients and $82(37 \%)$ AMI, had a much higher incidence of AMI because this group consisted only of admitted patients (personal communication, Michael C. Kontos, Virginia Commonwealth University, August 2012).

More recent studies confirm the low incidence of AMI and STEMI in these patients. Joshil et al. [51] reported on 177 LBBB patients referred for primary PCI (pPCI). Of 
these, 47 (26.5\%) had AMI, but only $9(5 \%)$ had $>70 \%$ stenosis, only $6(3.4 \%)$ had pPCI, and only one had $100 \%$ occlusion. Jain et al. reported that, of $35 \mathrm{LBBB}$ patients with suspected ACS referred to The Mayo Clinic over 5 years for pPCI, only 14 had ACS (12 AMI), and only five had occluded culprit arteries [52].

Finally, after adjustment for multiple differences, patients with LBBB who undergo reperfusion therapy for suspected AMI have a better prognosis than STEMI patients with normal conduction (OR for in-hospital mortality, 0.610, CI 0.571-0.655) because they do not, unlike the STEMI patients, actually have occlusion [53].

In spite of the fact that LBBB patients who do actually have AMI have a worse prognosis than those with normal conduction, clinicians have never consistently followed the ACC/AHA guidelines [54]. Therefore, it is critical to find an accurate means of diagnosing STEMI in the presence of LBBB on the ECG. Unfortunately, the Sgarbossa criteria have not succeeded, partly because the third criterion is not sensitive and specific enough [55], and partly because it has not been widely evaluated using angiography as an endpoint; instead the usual endpoint has been AMI as diagnosed by CK-MB, and this definition includes non-STEMI. ECGs with normal conduction have only $45 \%$ sensitivity for all AMI, but good sensitivity for STEMI [56-59].

We found in a retrospective study of 33 patients with LBBB and occlusion, compared to 129 without occlusion (including 24 with biomarker diagnosed AMI), that a refinement of the Sgarbossa rule which replaces the third component (excessively discordant STE as defined by $\geq 5 \mathrm{~mm}$ ) with a proportional definition (absolute value of $\mathrm{ST} / \mathrm{S}$ ratio $\geq 0.25)$, was more sensitive $(91 \%)$ than either the weighted Sgarbossa rule $(52 \%)$ or the unweighted rule (67\%). The specificity $(90 \%)$ was lower than the original rule $(98 \%)$ but the same as the unweighted rule. It was more accurate than either, both of which use a $5 \mathrm{~mm}$ absolute number [22••, 23-25, 60, 61]. Because we used a very strict angiographic occlusion endpoint rather than biomarker-diagnose AMI, the sensitivity of both rules was far higher than in previous studies, but conforms with studies of angiographic balloon occlusion [62]. We believe that the ECG is indeed sensitive and specific for complete occlusion, and that it remains the central test in determining need for emergency reperfusion, even in patients with LBBB.

Importantly, we found that another rule, any excessively discordant ST elevation or ST depression (as defined by the absolute value of the $\mathrm{ST} / \mathrm{S}$ ratio or $\mathrm{ST} / \mathrm{R}$ ratio $\geq 0.30$ ), was the most sensitive and specific of all. However, as this does not use ST elevation, it may not be widely accepted. Optimally, there would be validation studies of both rules and of the optimal cutpoints of $\geq 0.25$ and $\geq 0.30$.
Lead aVR in Acute Coronary Syndromes

There is a body of literature in the past decade on the significance of STE in lead aVR in ACS, and especially for its significance for diagnosis of left main coronary artery (LMCA) obstruction and three-vessel disease [63-68]. The literature is confusing for a few reasons. First, studies do not always clearly distinguish patients with and without STEMI. Second, LMCA "obstruction" is rarely defined, leaving it ambiguous as to whether the obstruction is (1) complete, (2) incomplete (subtotal), (3) complete but with good collateral circulation or (4) intermittent. Third, the studies were nearly all small with a retrospectively identified group with LMCA ACS. Fourth, findings may be influence by individual anatomy, ischemic preconditioning, and the timing of ECG recording. Since patients with LMCA occlusion do not often survive to the cath lab, the pretest probability for any positive ECG findings is low, and any reported sensitivities and specificities may distort the clinician's assessment of the actual presence of disease.

\section{Lead aVR in STEMI}

Lead aVR in STEMI is touted as important for recognizing LMCA occlusion [68]. Since patients with STEMI are already identified as a group which needs immediate reperfusion therapy, the primary importance of recognizing LMCA involvement in STEMI is (1) to recognize the increased mortality associated with this finding and (2) in the potential to avoid thienopyridine (e.g., clopidogrel) administration in such patients who are likely to need CABG and may suffer from excessive bleeding if they do receive a thienopyridine.

Only $0.19-1.3 \%$ of STEMI patients have LMCA occlusion, or $0.42-3 \%$ of anterior STEMI $[69,70]$, partly because patients with occlusion (or obstruction) do not frequently survive to the cath lab. Mortality is $50 \%$, and over $70 \%$ present in cardiogenic shock, such that the diagnosis of severe ACS and need for cath lab activation is usually apparent from the clinical presentation, rather than the ECG. In contrast, approximately $10 \%$ of patients with anterior STEMI have STE of at least $1 \mathrm{~mm}$ in aVR (as measured at $60 \mathrm{~ms}$ after the J-point) [66], and $25 \%$ have at least $0.5 \mathrm{~mm}$ STE in aVR (as measured at $60 \mathrm{~ms}$ after the J-point, relative to the TP segment) [63]. STE or STD of $1 \mathrm{~mm}$ or more in anterior STEMI portended a worse prognosis (compared to no STE or STD), even after correcting for STE or STD elsewhere on the ECG, but only ST depression in aVR ("reciprocal to injury in the area of lead V7") remained significant when corrected for all other ECG and clinical factors [66]. STE in aVR of at least $0.5 \mathrm{~mm}$ in anterior STEMI predicts septal AMI (occlusion 
of the LAD proximal to the first septal perforator) with a PPV and NPV of $70 \%$ and $80 \%[63]$ better than STE in V1, which at a cutoff of $>2.5 \mathrm{~mm}$ had $12 \%$ sensitivity and $100 \%$ specificity, with PPV and NPV of 100 and $39 \%$ [71]. Kotoku et al. [64] similarly found that STE in aVR correlated with proximal (vs. distal) LAD occlusion and was negatively correlated with a long (vs. short), or wraparound, LAD that affected the inferior wall. This is intuitive, as a proximal occlusion would lead to basal wall STEMI (see below), and distal occlusion of a wraparound (long, "type III") LAD would lead to inferior STE which would reciprocally attenuate the STE in aVR, or lead to STD in aVR. To be complete, Wong also found that STE in aVR in inferior STEMI conferred worse outcomes [66].

The study by Yamaji et al. [72] is cited as evidence that $\mathrm{STE}$ in aVR $>\mathrm{STE}$ in V1 is $81 \%$ sensitive and $80 \%$ specific for identifying the LMCA as the culprit [incidentally, this study has been cited among the general ACS literature; [68] however, it applies to STEMI only, as methods required TIMI $0-1$ flow]. If its conclusions are accurate, and one considers that $0.4-3 \%$ of LMCA occlusions make it to the cath lab alive, then the positive predictive value (PPV) of STE in aVR $>$ STE in V1 is only 1.6-11\%, rendering this finding useless. Furthermore, in the study by Kurisu et al. [70] of consecutive STEMI, written as a letter, 25 (about $3 \%$ of those with anterior STE) had LMCA occlusion; they compared ECG measurements of the 25 LMCA occlusions to only 30 each of consecutive LAD, RCA, and circumflex occlusions and found sensitivity and specificity for LMCA, vs. LAD, of STE in aVR $>$ STE in V1 of $40 \%$ and $93 \%$, resulting in a PPV of only $15 \%$.

A suggested explanation for $\mathrm{STE}$ in $\mathrm{aVR}>\mathrm{V} 1$ in LMCA STEMI (due to occlusion) is that aVR overlies the injured basal septum. The STE registered in V1, and presumably also other right precordial leads V2-V4, is partly attenuated by the reciprocal ST depression of the posterior wall STEMI that is due to obstruction of flow in the circumflex artery. The most likely explanation for STE in both aVL and aVR is similar: in addition to anterior and basal septal STEMI, there is high lateral STEMI from absence of circumflex, such that the ST vector is superior (a "superior" STEMI), as well as anterior [65].

\section{Lead aVR in Non-STE-ACS}

Lead aVR has been ignored in the past because it is $180^{\circ}$ opposite from an imaginary lead between leads I and II, and therefore would provide no independent data. More recent claims that ST elevation in aVR is independent of ST depression in these opposing leads have not been substantiated for non-STEMI, though this appears to be true for STEMI (see above). Nevertheless, it is convenient to use one lead with ST elevation (aVR) as a substitute for many others with ST depression, such that, in nonSTE-ACS, the degree of ST elevation in aVR correlates with the number of leads with ST depression, the depth of the ST depression, and the sum of ST depressions [67, 73-76]. In all studies, measurements of the ST segment are at $80 \mathrm{~ms}$ after the J-point for ST depression and $20 \mathrm{~ms}$ after the J-point for ST elevation, both relative to the TP segment.

To very briefly summarize the literature, diffuse ST depression has a good PPV and NPV for three-vessel and left main disease [73, 77]. The degree of STE in aVR, though not independent of ST depression, has strong association with outcome independent of clinical factors such as Killip class and blood pressure [74, 76]. Barrabes et al. [74] studied 775 non-STEMIs and found that, compared to no STE in aVR, STE of 0.5 to $1.0 \mathrm{~mm}$ had odds ratio (OR) for death of $4.2(1.5-12.2)$, and STE of $\geq 1.0 \mathrm{~mm}$ had OR of 6.6 (2.5-17.6). There were 475 who underwent angiography; of those with $\geq 1 \mathrm{~mm}$ of STE in aVR $(n=92), 48 \%$ had three-vessel disease and $18 \%$ had LMCA disease, compared to 21 and $4 \%$ for those with $<1 \mathrm{~mm}$ STE in aVR [74]. Kosuge et al. [75] studied 310 patients with ACS without STE. They found that STE in aVR of $\geq 0.5 \mathrm{~mm}$ was the strongest predictor of LMCA or three-vessel disease, with an OR of 19.7, and it identified LMCA or three-vessel disease with $78 \%$ sensitivity and $86 \%$ specificity, and a PPV and NPV of 57 and $95 \%$. Finally, Szymanski et al. in 2008 found mortality correlated with the degree of STE in lead aVR, independent of TIMI score, and was highly associated with ST depression in multiple locations.

In 2011, Kosuge et al. [67] studied 572 patients with non-STE-ACS; among the 196 with a positive troponin $\mathrm{T}$ on admission, the sensitivity and specificity of $\mathrm{STE} \geq 1.0 \mathrm{~mm}$ in aVR for LMCA or three-vessel disease was 80 and $93 \%$, with a PPV of $56 \%$ and an NPV of $98 \%$, and accuracy of $92 \%$. OR of degree of STE in aVR for severe three-vessel or LMCA disease among all patients was 29 (9.5-50). CABG was undertaken in $46 \%$ of those with severe 3-vessel or LMCA disease vs. $2 \%$ of those without. The authors suggest withholding clopidogrel in patients with non-STEMI and STE in aVR of at least $1 \mathrm{~mm}$.

\section{Summary of Lead aVR in ACS}

Thus, STE in aVR in non-STEMI, though not independent of ST depression elsewhere, is a good approximation of the sum of STD and is a very useful predictor of poor outcomes and of need for CABG, independent of other clinical data. STE in aVR is generally reciprocal to diffuse ST depression, opposite to a negative ST vector towards I, II, 
and V5, and is a result of subendocardial ischemia. On the other hand, the STE in aVR in STEMI, usually anterior STEMI, is more likely a result of transmural injury (STEMI of the basal septum). In this latter case the STE in aVR is not reciprocal to any ST depression, but directly indicative of injury.

Finally, the most relevant practical applications are:

(1) In non-STEMI, if there is STE in aVR $\geq 1.0 \mathrm{~mm}$, it may be prudent to withhold clopidogrel

(2) In both STEMI and non-STEMI, the degree of STE in aVR correlates with worse disease and worse outcomes, independent of the clinical presentation; these patients must be treated aggressively with early angiography and revascularization.

\section{Conclusion}

It remains a challenge to appropriately apply reperfusion therapy to patients with ischemia symptoms. Although the ECG is the first critical test, its accuracy as applied today is not optimal. There have recently been a few studies using angiographic outcomes to attempt to find features of the ECG which correlate highly with coronary obstruction and can help to detect electrocardiographically subtle STEMI and differentiate it from the look-alikes. The key ones are described here. I hope for more such research in the future.

Disclosure No potential conflicts of interest relevant to this article were reported.

\section{References}

Papers of particular interest, published recently, have been highlighted as:

- Of importance

-• Of major importance

1. Jayroe JB, Spodick DH, Nikus K, et al. Differentiating ST elevation myocardial infarction and nonischemic causes of ST elevation by analyzing the presenting electrocardiogram. Am J Cardiol. 2009;103(3):301-6.

2. Turnipseed SD, Bair AE, Kirk JD, Diercks DB, Tabar P, Amsterdam EA. Electrocardiogram differentiation of benign early repolarization versus acute myocardial infarction by emergency physicians and cardiologists. Acad Emerg Med. 2005; 12(5 Suppl 1):85-6.

3. Tran V, Huang HD, Diez JG, et al. Differentiating ST-elevation myocardial infarction from nonischemic ST-elevation in patients with chest pain. Am J Cardiol. 2011;108(8):1096-101.

4. Eagle KA, Nallamothu BK, Mehta RH, et al. Trends in acute reperfusion therapy for ST-segment elevation myocardial infarction from 1999 to 2006: we are getting better but we have got a long way to go. Eur Heart J. 2008;29(5):609-17.
5. Barron HV, Bowlby LJ, Breen T, et al. Use of reperfusion therapy for acute myocardial infarction in the United States: data from the national registry of myocardial infarction 2. Circulation. 1997;97(12):1150-6.

6. Krumholz HM, Murillo JE, Chen J, et al. Thrombolytic therapy for eligible elderly patients with acute myocardial infarction. JAMA. 1997;277(21):1683-8.

7. Tricomi AJ, Magid DJ, Rumsfeld JS, et al. Missed opportunities for reperfusion therapy for ST-segment elevation myocardial infarction: results of the Emergency Department Quality in Myocardial Infarction (EDQMI) study. Am Heart J. 2008;155(3): $471-7$.

8. - Wang T, Zhang M, Fu Y, et al. Incidence, distribution, and prognostic impact of occluded culprit arteries among patients with non-ST-elevation acute coronary syndromes undergoing diagnostic angiography Am Heart J. 2009;157(4):716-23. These articles demonstrates that a high proportion of "Non-STEMIs" have an occluded infarct-related artery, and that these patients have worse outcomes. This demonstrates that the standard definition of STEMI, which is dependent upon criterion-based ECG findings such as millimeters of ST elevation, is insufficient to identify patients with ACS who have occlusion, and that more work needs to be done to identify such patients, whether using the ECG or other modalities.

9. From AM, Best PJM, Lennon RJ, Rihal CS, Prasad A. Acute myocardial infarction due to left circumflex artery occlusion and significance of ST-segment elevation. Am J Cardiol. 2010; 106(8):1081-5.

10. Rokos IC, French WJ, Mattu A, et al. Appropriate cardiac cath lab activation: optimizing electrocardiogram interpretation and clinical decision-making for acute ST-elevation myocardial infarction. Am Heart J. 2010;160(6):995-1004.

11. Adams J, Trent R, Rawles JM, On behalf of the GREAT Group. Earliest electrocardiographic evidence of myocardial infarction: implication for thrombolytic treatment. BMJ. 1993;307:409-13.

12. Stone GW, Cox D, Garcia E, et al. Normal flow (TIMI-3) before mechanical reperfusion therapy is an independent determinant of survival in acute myocardial infarction: analysis from the primary angioplasty in myocardial infarction trials. Circulation. 2001; 104(6):636-41.

13. Kontos MC, Kurz MC, Roberts CS, et al. An evaluation of the accuracy of emergency physician activation of the cardiac catheterization laboratory for patients with suspected ST-segment elevation myocardial infarction. Ann Emerg Med. 2010;55(5): 423-30.

14. Larson DM, Menssen KM, Sharkey SW, et al. "False-Positive" cardiac catheterization laboratory activation among patients with suspected ST-segment elevation myocardial infarction. JAMA. 2007;298(23):2754-60.

15. Smith SW, Khalil A, Henry TD, et al. Electrocardiographic differentiation of early repolarization from subtle anterior ST-segment elevation myocardial infarction. Ann Emerg Med. 2012; 60(1):45-56.

16. Garvey JL, Monk L, Granger CB, et al. Rates of cardiac catheterization cancelation for ST-segment elevation myocardial infarction after activation by emergency medical services or emergency physicians: results from the North Carolina catheterization laboratory activation registry. Circulation. 2012;125(2): 308-13.

17. Sawyer KN, Robinson AL, Roberts CS, Kurz MC, Kontos MC. Prevalence and ECG findings for patients with false-positive cardiac catheterization laboratory activation among patients with suspected ST-segment elevation myocardial infarction (Abstract 189). Acad Emerg Med. 2012;19(s1):S102-3.

18. Barge-Caballero E, Vazquez-Rodriguez JM, Estevez-Loureiro R, et al. Prevalence, etiology and outcome of catheterization 
laboratory false alarms in patients with suspected ST-elevation myocardial infarction. Rev Esp Cardiol. 2010;63(5):518-27.

19. McCabe JM, Armstrong EJ, Kulkarni A, et al. Prevalence and factors associated with false-positive ST-segment elevation myocardial infarction diagnoses at primary percutaneous coronary intervention-capable centers: a report from the activate-SF registry. Arch Intern Med. 2012;172:864-71.

20. Bachour F, Asinger R. Activating primary percutaneous coronary intervention for STEMI that is not: comment on "prevalence and factors associated with false-positive ST-Segment elevation myocardial infarction diagnoses at primary percutaneous coronary intervention-capable centers". Arch Intern Med. 2012; 871-2.

21. Kontos MC, Aziz HA, Chau VQ, Roberts CS, Ornato JP, Vetrovec GW. Outcomes in patients with chronicity of left bundle-branch block with possible acute myocardial infarction. Am Heart J. 2011;161(4):698-704.

22. • Smith SW, Dodd KW, Henry TD, Dvorak DM, Pearce LA. Diagnosis of ST elevation myocardial infarction in the presence of left bundle branch block using the ST elevation to S-wave ratio in a modified Sgarbossa rule. Ann Emerg Med. 2012; 60(6):766-76. This article demonstrates that millimeter criteria of ST-segment elevation are very poor at differentiating anterior $S T E M I$ from early repolarization, that the $R$-wave amplitude is more important than ST elevation, and that by using three variables, ST elevation, R-wave amplitude, and corrected QT interval, one can differentiate the two entities with a high degree of accuracy

23. Smith SW. Electrocardiographic diagnosis of ST-elevation myocardial infarction in the presence of left bundle branch block. Peer-reviewed lecture. Acad Emerg Med. 2012;19(5):593.

24. Dodd KW, Aramburo L, Henry TD, Smith SW. Ratio of discordant ST segment elevation or depression to QRS complex amplitude is an accurate diagnostic criterion of acute myocardial infarction in the presence of left bundle branch block (Abstract 551). Circulation. 2008;118(18 Supplement):S_578.

25. Dodd KW, Aramburo L, Broberg E, Smith SW. For diagnosis of acute anterior myocardial infarction due to left anterior descending artery occlusion in left bundle branch block, High ST/ S Ratio is more accurate than convex ST segment morphology (Abstract 583). Acad Emerg Med. 2010;17(S1):S196.

26. Antman EM, Tanasijevic MJ, Thompson B, et al. Cardiac-specific troponin I levels to predict the risk of mortality in patients with acute coronary syndromes. N Engl J Med. 1996;335:1342-9.

27. Hallen J, Buser P, Schwitter J, et al. Relation of cardiac troponin I measurements at 24 and 48 hours to magnetic resonance-determined infarct size in patients with ST-elevation myocardial infarction. Am J Cardiol. 2009;104(11):1472-7.

28. Chia S, Senatore F, Raffel OC, Lee H, Wackers FJ, Jang IK. Utility of cardiac biomarkers in predicting infarct size, left ventricular function, and clinical outcome after primary percutaneous coronary intervention for ST-segment elevation myocardial infarction. Jacc. 2008;1(4):415-23.

29. Dumas F, Manzo-Silberman S, Fichet J, et al. Can early cardiac troponin I measurement help to predict recent coronary occlusion in out-of-hospital cardiac arrest survivors. Crit Care Med. 2012;40:1777-84.

30. Turnipseed SD, Lang K, Laurin EG, Diercks DB. Prevalence of ST-segment elevation myocardial infarction in patients with J-point notching on initial emergency department electrocardiograms (Abstract 188). Ann Emerg Med. 2010;56(3 Suppl):S62-3.

31. Macfarlane PW, Browne D, Devine B, et al. Modification of ACC/ESC criteria for acute myocardial infarction. J Electrocardiol. 2004;37(Suppl):98-103.

32. Wagner GS, Macfarlane P, Wellens $H$, et al. AHA/ACCF/HRS recommendations for the standardization and interpretation of the electrocardiogram: part VI: acute ischemia/infarction: a scientific statement from the American Heart Association Electrocardiography and Arrhythmias Committee, Council on Clinical Cardiology; the American College of Cardiology Foundation; and the Heart Rhythm Society. Endorsed by the International Society for Computerized Electrocardiology. J Am Coll Cardiol. 2009; 53(11):1003-11.

33. - Verouden NJ, Koch KT, Peters RJ, et al. Persistent precordial 'hyper acute' T-waves signify proximal LAD artery occlusion. Heart 2009;95:1701-6. This paper describes fully, for the first time, an uncommon but important ECG manifestation of LAD occlusion: ST depression followed by a large T-wave

34. Marriott HJL. Practical electrocardiography. 7th ed. Baltimore: Williams and Wilkins; 1983.

35. Smith SW, Zvosec DL, Henry TD, Sharkey SW, editors. The ECG in acute MI: an evidence-based manual of reperfusion therapy. 1st ed. Philadelphia: Lippincott, Williams and Wilkins; 2002.

36. Soo CS. Tall precordial T waves with depressed ST take-off: an early sign of acute myocardial infarction. Singapore Med J. 1995;36(2):236-7.

37. Bischof J, Thompson RP, Tikkanen JT, et al. ST Depression in AVL differentiates inferior ST elevation myocardial infarction from benign causes of inferior ST elevation (Abstract 21). Ann Emerg Med. 2012;60(4 Suppl):S8-9.

38. Spodick DH. The electrocardiogram in acute pericarditis: distributions of morphologic and axial changes in stages. Prog Cardiovasc Dis. 1974;33:470-4.

39. Spodick DH. Differential characteristics of the electrocardiogram in early repolarization and acute pericarditis. $\mathrm{N}$ Engl $\mathrm{J}$ Med. 1976;295(10):523-6.

40. Henning DJ, Fjaeldstad AE, Moeller CM, Fogel M, Fischer CM, Ullman EA. Evaluating a rule for differentiating pericardial disease from ST-segment elevation myocardial infarction. Acad Emerg Med. 2011;18(1 Suppl):S16.

41. Goitein O, Matetzky S, Beinart R, et al. Acute myocarditis: noninvasive evaluation with cardiac MRI and transthoracic echocardiography. Ajr. 2009;192(1):254-8.

42. Dorfman TA, Aqel R. Regional pericarditis: a review of the pericardial manifestations of acute myocardial infarction. Clin Cardiol. 2009;32(3):115-20.

43. Sarda L, Colin P, Boccara F, et al. Myocarditis in patients with clinical presentation of myocardial infarction and normal coronary arteries. J Am Coll Cardiol. 2001;37(3):786-92.

44. Antman EM, Anbe DT, Armstrong PW, et al. ACC/AHA guidelines for the management of patients with ST-elevation myocardial infarction-executive summary. A report of the American College of Cardiology/American Heart Association Task Force on practice guidelines (Writing Committee to revise the 1999 guidelines for the management of patients with acute myocardial infarction). J Am Coll Cardiol. 2004;44(3):671-719.

45. Kushner FG, Hand M, Smith SC Jr, et al. 2009 focused updates: ACC/AHA guidelines for the management of patients with ST-elevation myocardial infarction (updating the 2004 guideline and 2007 focused update) and ACC/AHA/SCAI guidelines on percutaneous coronary intervention (updating the 2005 guideline and 2007 focused update) a report of the American College of Cardiology Foundation/American Heart Association Task Force on practice guidelines. J Am Coll Cardiol. 2009;54(23): 2205-41.

46. Antman EM, Hand M, Armstrong PW, et al. 2007 focused update of the ACC/AHA 2004 guidelines for the management of patients with ST-elevation myocardial infarction. J Am Coll Cardiol. 2008;51(2):210-47.

47. Kontos MC, McQueen RH, Jesse RL, Tatum JL, Ornato JP. Can myocardial infarction be rapidly identified in emergency 
department patients who have left bundle branch block? Ann Emerg Med. 2001;37(5):431-8.

48. Li SF, Walden PL, Marcilla O, Gallagher EJ. Electrocardiographic diagnosis of myocardial infarction in patients with left bundle branch block. Ann Emerg Med. 1999;36(6):561-6.

49. Chang AM, Shofer FS, Tabas JA, Magid DJ, McCusker CM, Hollander JE. Lack of association between left bundle-branch block and acute myocardial infarction in symptomatic ED patients. Am J Emerg Med. 2009;27(8):916-21.

50. Roe MT, Parsons LS, Pollack CV Jr, et al. Quality of care by classification of myocardial infarction: treatment patterns for STsegment elevation vs non-ST-segment elevation myocardial infarction. Arch Intern Med. 2005;165(14):1630-6.

51. Joshil NV, Bawamia BR, Jamieson S, Zaman A, Edwards R. Evaluating a nurse led triage process in treating patients with left bundle branch block (LBBB) referred for primary percutaneous coronary intervention (pPCI) (Abstract). Heart. 2011;97(Suppl 1):A10.

52. Jain S, Ting HT, Bell M, et al. Utility of left bundle branch block as a diagnostic criterion for acute myocardial infarction. Am J Cardiol. 2011;107(8):1111-6.

53. Poon K, Frederick PD, French WJ. Does a new or presumed new left bundle branch block have equivalent mortality to an acute ST-elevation myocardial infarction? (Abstract 4317). Circulation 2009;120(18_Suppl_2):S935.

54. Archbold RA, Ranjadayalan K, Suliman A, Knight CJ, Deaner A, Timmis AD. Underuse of thrombolytic therapy in acute myocardial infarction and left bundle branch block. Clin Cardiol. 2010;33(3):E25-9.

55. Tabas JA, Rodriguez RM, Seligman HK, Goldschlager NF. Electrocardiographic criteria for detecting acute myocardial infarction in patients with left bundle branch block: a metaanalysis. Ann Emerg Med. 2008;52(4):329-36.

56. Fesmire FM, Percy RF, Bardoner JB, Wharton DR, Calhoun FB. Usefulness of automated serial 12-lead ECG monitoring during the initial emergency department evaluation of patients with chest pain. Ann Emerg Med. 1998;31(1):3-11.

57. Fesmire FM, Percy RF, Wears RL, MacMath TL. Initial ECG in $\mathrm{Q}$ wave and non-Q wave myocardial infarction. Ann Emerg Med. 1989;18(7):741-6.

58. Rouan GW, Lee TH, Cook EF, Brand DA, Weisberg MC, Goldman L. Clinical characteristics and outcome of acute myocardial infarction in patients with initially normal or nonspecific electrocardiograms (a report from the multicenter chest pain study). Am J Cardiol. 1989;64(18):1087-92.

59. Rude RE, Poole WK, Muller J, et al. Electrocardiographic and clinical criteria for recognition of acute myocardial infarction based on analysis of 3,697 patients. Am J Cardiol. 1983;52(8): 936-42.

60. Smith SW. Electrocardiographic research on left bundle branch block must use angiographic outcomes and proportionality if it is to guide reperfusion therapy. Ann Emerg Med. 2009;53(5): 691-2.

61. Smith SW, Heegaard W, Bachour FA, Brady WJ. Acute myocardial infarction with left bundle-branch block: disproportional anterior ST elevation due to right ventricular myocardial infarction in the presence of left bundle-branch block. Am J Emerg Med. 2008;26(3):342-7.

62. Stark KS, Krucoff MW, Schryver B, Kent KM. Quantification of ST-segment changes during coronary angioplasty in patients with left bundle branch block. Am J Cardiol. 1991;67(15):1219-22.
63. Aygul N, Ozdemir K, Tokac M, et al. Value of lead aVR in predicting acute occlusion of proximal left anterior descending coronary artery and in-hospital outcome in ST-elevation myocardial infarction: an electrocardiographic predictor of poor prognosis. J Electrocardiol. 2008;41(4):335-41.

64. Kotoku M, Tamura A, Abe Y, Kadota J. Determinants of STsegment level in lead aVR in anterior wall acute myocardial infarction with ST-segment elevation. J Electrocardiol. 2009; 42(2):112-7.

65. Nikus KC, Eskola MJ. Electrocardiogram patterns in acute left main coronary artery occlusion. J Electrocardiol. 2008;41(6): $626-9$.

66. Wong CK, Gao W, Stewart RA, French JK, Aylward PE, White HD. The prognostic meaning of the full spectrum of aVR STsegment changes in acute myocardial infarction. Eur Heart J. 2012;33(3):384-92.

67. Kosuge M, Ebina T, Hibi K, et al. An early and simple predictor of severe left main and/or three-vessel disease in patients with non-ST-segment elevation acute coronary syndrome. Am J Cardiol. 2011;107(4):495-500.

68. Lead aVR: importance of the "Forgotten 12th Lead" in patients with ACS. medscape emergency medicine. 2009. http://www. medscape.com/viewarticle/589781. Accessed 20 July 2012.

69. Zoghbi GJ, Misra VK, Brott BC, et al. ST elevation myocardial infarction due to left main culprit lesions: percutaneous coronary intervention outcomes free. J Am Coll Cardiol. 2010;55(10s1): E1712.

70. Kurisu S, Inoue I, Kawagoe T, et al. Electrocardiographic features in patients with acute myocardial infarction associated with left main coronary artery occlusion. Heart. 2004;90(9):1059-60.

71. Engelen DJ, Gorgels AP, Cheriex EC, et al. Value of the electrocardiogram in localizing the occlusion site in the left anterior descending coronary artery in acute myocardial infarction. J Am Coll Cardiol. 1999;34(2):389-95.

72. Yamaji H, Iwasaki K, Kusachi S, et al. Prediction of acute left main coronary artery obstruction by 12-lead electrocardiography. ST segment elevation in lead aVR with less ST segment elevation in lead V(1). J Am Coll Cardiol. 2001;38(5):1348-54.

73. Gorgels AP, Vos MA, Mulleneers R, de Zwaan C, Bar FW, Wellens HJ. Value of the electrocardiogram in diagnosing the number of severely narrowed coronary arteries in rest angina pectoris. Am J Cardiol. 1993;72(14):999-1003.

74. Barrabes JA, Figueras J, Moure C, Cortadellas J, Soler-Soler J. Prognostic value of lead aVR in patients with a first non-STsegment elevation acute myocardial infarction. Circulation. 2003;108(7):814-9.

75. Kosuge M, Kimura K, Ishikawa T, et al. Predictors of left main or three-vessel disease in patients who have acute coronary syndromes with non-ST-segment elevation. Am J Cardiol. 2005; 95(11):1366-9.

76. Szymanski FM, Grabowski M, Filipiak KJ, Karpinski G, Opolski G. Admission ST-segment elevation in lead aVR as the factor improving complex risk stratification in acute coronary syndromes. Am J Emerg Med. 2008;26(4):408-12.

77. Barrabes JA, Figueras J, Moure C, Cortadellas J, Soler-Soler J. Prognostic significance of ST segment depression in lateral leads I, aVL, V5 and V6 on the admission electrocardiogram in patients with a first acute myocardial infarction without ST segment elevation. J Am Coll Cardiol. 2000;35(7):1813-9. 